\title{
Políticas Públicas em Saúde do Trabalhador: campo prático e de disputa simbólica
}

\section{Public Policies in Workers' health: symbolic dispute field \\ Política Pública de Salud Ocupacional: campo práctico de la controversia simbólica}

\section{Andréa Luiza da Silveira*}

Universidade Comunitária da Região de Chapecó - Unochapecó, Santa Catarina, Brasil

\author{
Álvaro Roberto Crespo Merlo** \\ Universidade Federal do Rio Grande do Sul - UFRGS, Porto Alegre, Rio Grande do \\ Sul, Brasil
}

\begin{abstract}
RESUMO
Objetivamos analisar a Política Nacional de Saúde do Trabalhador e da Trabalhadora, considerando-se as interfaces com a Política Nacional de Segurança e Saúde do Trabalhador e com o Plano Nacional de Segurança e Saúde do Trabalhador. A partir da organização das políticas em corpus de análise, discriminamos seus conceitos norteadores e encontramos contradições entre eles que podem caracterizar uma disputa simbólica, no âmbito da prática profissional, e que a política tem a missão de iluminar. Deste modo, a PNSTT de 2012 desvela-se em três dimensões: biopolítica, campo de disputa simbólica e campo prático. Situar as suas contradições, inicialmente, pode ser importante para viabilizá-la mediante as possibilidades que ela comporta e no contexto social em disputa onde ela se situa. Entendemos, no entanto, que as pesquisas nos serviços de saúde deverão contribuir para compreender, ainda mais, as dimensões que localizamos.
\end{abstract}

Palavras-chave: políticas, saúde, trabalhador, profissional.

\begin{abstract}
In this article, we aim at analyzing the Política Nacional de Saúde do Trabalhador e da Trabalhadora - PNSTT (National Health Policies for Male and Female Workers) as an interface with the National Policy for Workers' Safety and Health and the National Plan for Workers' Health and Safety . From the organization of the main policies into a corpus, we were able to discriminate their guiding concepts and to visualize the contractions within these concepts in what concerns the symbolic disputes in the professional practices such policies are intended to regulate. Therefore, the PNSTT of 2012 acquires three distinct dimensions: biopolicy, symbolic dispute field and practical field. Placing these contradictions within the scope of analysis of these policies is viable in face of the possibilities that they embrace and within the social context in dispute where they exist. Thus, we understand
\end{abstract}


that the research conducted in health service programs that are associated with these policies should contribute to better comprehend the dimensions we identified.

Keywords: policies, workers', health, professional.

\section{RESUMEN}

El objetivo fue analizar la Política Nacional de Salud del Trabajador y de la Trabajadora - PNSTT, teniendo en cuenta la interfaz con la Política Nacional de Seguridad y Salud en el Trabajo - PNSST y el Plan Nacional para la Seguridad y Salud Ocupacional. Organizamos las políticas en corpus de análisis, discriminamos sus conceptos rectores y encontramos contradicciones entre ellos que pueden caracterizar una disputa simbólica en el contexto de la práctica profesional que la política prevé. Por lo tanto, PNSTT de 2012 se desarrolla en tres dimensiones: la biopolítica, el terreno de juego simbólico y lo campo de la práctica profesional. Situar sus contradicciones inicialmente, puede ser importante para hacerlo viable nel contexto social en que se encuentra. Entendemos, sin embargo, que la investigación en servicios de salud, podrá mostrar las dimensiones que hemos encontrado.

Palabras clave: políticas, salud, trabajador, professional.

\section{Políticas Públicas em Saúde do Trabalhador: campo de disputa simbólica}

A consolidação das políticas públicas no campo da saúde do trabalhador, instituídas a partir de 2011, torna-se ainda mais desafiadora em virtude de ocorrer num período em que a precarização do trabalho se acirra. Desde 1995, quando o Consenso de Washington, que reuniu o Fundo Monetário Internacional - FMI - o Banco Mundial e o Departamento do Tesouro dos Estados Unidos, definiu a política neoliberal propondo ajustes estruturais para países em desenvolvimento, o trabalho assalariado é ameaçado juntamente com as garantias legais e protetivas das políticas sociais. Ao mesmo tempo, o trabalho como categoria ontológica vinha sendo repensado no que diz respeito a sua centralidade para discutir-se as relações econômicas e de produção e a constituição do sujeito. Nesse contexto, o Estado ora promove as políticas sociais, ora tende a minimizá-las.

Foucault (2008) propõe como problema de análise a arte de governar tanto quanto a prática quanto a significação. Afirma no que se refere à prática, que o neoliberalismo, diferente do liberalismo, "é uma política de sociedade" (200), visto que, "ele apresenta como um projeto de sociedade, isto é, ele fará exatamente da sociedade o alvo e o objeto de sua prática governamental." (idem) O autor pretende desvelar "uma nova arte de governar" cujo objeto de ação é o ambiente social. E, no que diz respeito à significação, pensa que "As palavras, afinal, querem dizer o que [dizem], e a trajetória das palavras indica de fato os processos que elas podem indicar." (idem) 
Em suma, permite compreender através de suas investigações que o ambiente social torna-se também mercado, e as relações, então, constituem a dinâmica concorrencial em vez das trocas mercantis. Equivale dizer que o "homo eoconomicus, que se quer constituir não é o homem da troca, não é o homem consumidor, é o homem da empresa e da produção". (201)

Neste sentido, as políticas sociais advindas do Estado de Bem-Estar Social, propõem-se, como mostra Foucault (2008) ao explanar sobre a economia de bem-estar, a servir de "contrapeso a processos econômicos selvagens" (194) que terão como efeito a desigualdade social. Por isso trata-se de uma política que se volta a "uma socialização de certos elementos de consumo" (195) a exemplo da saúde. Admite, por fim, que o crescimento econômico se alinha ao crescimento das políticas sociais. São os princípios do Estado de BemEstar Social que serão questionados pela arte de governar neoliberal, no que tange as políticas sociais.

A governamentalidade neoliberal concebe a desigualdade igual para todos. Assim, em vez da socialização da política social prevê a política social individual. Os riscos inerentes a existência como o nascimento e a morte, aqueles provenientes do trabalho seja o adoecimento seja o acidente, serão assumidos pelo indivíduo que deverá ter renda suficiente para isso ou deverá agregar-se a outros indivíduos para proteger-se. No neoliberalismo, ainda segundo Foucault (2008), a política social tende a ser uma política social privatizada. No entanto, essa tendência, a rigor, ainda não se efetivou, pois as políticas sociais, enquanto apazíguam os conflitos típicos do neoliberalismo, vão de encontro a ele à medida que primam pela socialização do consumo e da renda e a coletivização dos riscos.

Neste sentido, objetivamos analisar as políticas públicas do Campo da Saúde do Trabalhador, sobretudo, a Política Nacional de Saúde do Trabalhador e da Trabalhadora, considerando sua interface com a Política Nacional de Segurança e Saúde do Trabalhador e o Plano Nacional de Segurança e Saúde do Trabalhador. Encontramos, então, os conceitos de população, ambiente e risco, coadunes ao de sociedade civil, que são próprios de uma biopolítica que pode estar mais vinculada a arte neoliberal de governar. Ao mesmo tempo em que nos deparamos com os conceitos de trabalho, processo de trabalho e experiência do trabalhador, ligados ao materialismo histórico dialético que tem certa propensão crítica ao neoliberalismo. Assim, pretendemos desvelar a PNSTT (2012) em três dimensões: biopolítica, campo de disputa simbólica e campo prático. 


\section{O método de análise}

Propomos centralmente a análise da PNSTT (Brasil, 2012) e sua interface com o a PNSST (Brasil, 2011) e o PLNSST (Brasil, 2012). A PNSST foi instituída pelo Decreto № 7.602, de 7 de novembro de 2011 (Brasil, 2011). Importante lembrar que o decreto é uma ação concernente ao poder executivo, normatizado pela Constituição Federal Brasileira. Alinhada a ele temos a publicação da PNSTT (Brasil, 2012) pela Portaria № 1.823, de 23 de agosto de 2012 do Ministério da Saúde. Com a função de efetivar a PNSST, a Comissão Tripartite de Saúde e Segurança no Trabalho - CT-SST - que tem a responsabilidade de gerir a PNSST segundo preceitos da gestão participativa, foi “[...] constituída paritariamente por representantes do governo, trabalhadores e empregadores, conforme ato conjunto dos Ministros de Estado do Trabalho e Emprego, da Saúde e da Previdência Social". (Brasil, 2011) A CT-SST constrói o PLANSAT que, além do resgate histórico das políticas, ligando-as tanto à Organização Internacional do Trabalho - OIT - quanto com a Organização Mundial de Saúde - OMS, "articula ações dos mais diferentes atores sociais em busca da aplicação prática da Política Nacional de Segurança e Saúde no Trabalho - PNSST, instituída pelo Decreto no 7.602 de 7 de novembro de 2011" (Brasil, 2012).

Esses três documentos formam um corpus tal como o define Bauer e Aarts (2015), um conjunto de materiais escolhidos arbitrariamente pelo pesquisador (a). Partimos dos seguintes pontos para definir 0 corpus, tal como Bauer e Aarts (2015) inspirados em Barthes. A relevância dos documentos para a discussão do tema; a homogeneidade do material, um decreto, uma portaria e um plano engendrado a partir das diretrizes do decreto, todos sobre política no campo da saúde do trabalhador; e, finalmente a sincronicidade, que se refere à historicidade dos documentos selecionados, tendo em vista que as políticas implementadas em 2011 e 2012, encontram-se em 2016 num processo de consolidação na rede SUS - Sistema Único de Saúde.

Definimos igualmente os conceitos que nortearam a análise: riscos e ambiente. $E$, por fim, mostramos que fazem certo contraponto com os conceitos de trabalho, processo de trabalho e experiência do trabalhador. A importância dos termos adotados por uma política é atestada pelo fato de que deverá nortear práticas no cotidiano. As políticas públicas direcionadas à saúde dos trabalhadores, com efeito, influenciarão as práticas de vigilância e assistência. Os conceitos, como as palavras, são constituídos por significantes que comporão a vivência em curso em certo nicho de práticas que constituem subjetividades e, no que concerne aos trabalhadores dos serviços, formas de refletir sobre as problemáticas que atravessam ou transversalizam o serviço de assistência e de vigilância. 
Nossa opção por destacar a palavra se justifica pelo fato de que ela expressa e contribui para significar o vivido na medida em que é tematizado. Segundo Sartre (2013) a palavra é, "uma essência objetiva constituída pela evolução histórica dos costumes, pela sabedoria das nações, por um valor positivo e muitas vezes por um anti-valor que atestam, ambos, as contradições da ideologia em vigor ou das ideologias que se opõe." (785) Portanto, dada a importância das terminologias adotadas em uma política, nos propomos a refletir sobre os conceitos contemplados na Política Nacional de Saúde do Trabalhador e da Trabalhadora - PNSTT (2012) e sua interface com a Política Nacional de Saúde e Segurança do Trabalhador (Brasil, 2011) e com o Plano de Saúde do Trabalhador e da Trabalhadora PLANSAT (Brasil, 2012) problematizando, de um lado, o uso das palavras risco e ambiente que nos parece referenciar o individualismo e a naturalização de demandas e práticas profissionais; e, de outro lado, o recurso aos conceitos de trabalho, processo de trabalho e experiência do trabalhador que remetem à coletividade e ao sujeito em sua subjetividade historicamente constituída.

\section{A PNSTT como uma biopolítica}

A biopolítica constitui-se por um conjunto de pressupostos e ações que escrutinam a população a partir de análises sobre esta mesma população, através de dados epidemiológicos tais como o número e condições de nascimento, de mortalidade e de adoecimento e sua ligação com os riscos sociais e ambientais. Os conceitos de risco e ambiente são característicos das biopolíticas, tal como o demonstra Foucault $(1979,2006,2008)$ e à medida que controla as condutas constituem a governamentalidade localizada, no caso que nos ocupa, no ambiente de trabalho referente à ocorrência de acidentes e ao adoecimento. O conceito de biopolítica foi mobilizado para a apreciação da PNSTT (Brasil, 2012), sobretudo, em função da incidência dos conceitos sociedade civil coadune aos conceitos de ambiente e risco.

Foucault (2008) afirma a importância do "papel de mostrar quais são os efeitos de saber que são produzidos em nossa sociedade pelas lutas, os choques, os combates que nela se desenrolam, e pelas táticas de poder que são os elementos dessa luta". (05) Tais indicações nos permitem pensar sobre um saber constituído na PNSTT (Brasil, 2012) como um campo de lutas que resultou numa política e, ao mesmo tempo, está em curso na sua efetivação. Neste ponto, Foucault (2008) oferece-nos um importante horizonte reflexivo, ao problematizar sobre o desejo e sua relação com o indivíduo ligado a certa perspectiva do neoliberalismo em relação aos 
interesses. Segundo o autor, desde um ponto de vista do neoliberalismo,

O desejo é a busca do interesse para o indivíduo. O indivíduo, de resto, pode perfeitamente se enganar, em seu desejo, quanto ao seu interesse pessoal, mas há uma coisa que não engana: que o jogo espontâneo, ou em todo caso, espontâneo e, ao mesmo tempo, regrado do desejo permitirá de fato a produção de um interesse, de algo que é interessante para a própria população. Produção do interesse coletivo pelo jogo do desejo: é o que marca ao mesmo tempo a naturalidade da população e a artificialidade possível dos meios criados para geri-la. (95)

As políticas às quais nos atemos propõem a regulação dos riscos a que certa população se submete em determinado ambiente. O próprio conceito de risco, qual seja, elementos do ambiente de trabalho que podem causar agravos aos trabalhadores expressa, de algum modo, a produção do desejo dos próprios trabalhadores sobre o controle dos riscos que envolvem certa experiência concreta dos trabalhadores no ambiente de trabalho. Neste sentido, a nossa leitura de Foucault $(2006,2008)$ nos possibilita compreender que o desejo do indivíduo que envolve certo interesse da população deve ser promovido pela sociedade civil organizada.

A PNSTT (Brasil, 2012) cumpre o seu papel de regular, controlar e normatizar enquanto atende à população segundo seus interesses, pois visa como promulga o seu artigo 2으, "a promoção e a proteção da saúde dos trabalhadores e a redução da morbimortalidade decorrente dos modelos de desenvolvimento e dos processos produtivos". Neste ponto, acresce-se que as ações, sobretudo de vigilância em saúde, deverão ser garantidas e garantir o controle social pela sociedade civil por meio da participação dos trabalhadores e profissionais dos serviços nos coletivos previstos pela política, a exemplo das conferências de saúde do trabalhador. Foucault (2008), ao assinalar que "um governo que respeita a especificidade da economia, será um governo que administrará a sociedade civil, que administrará a nação, que administrará a sociedade, que administrará o social" (403) nos ajuda a refletir sobre a função das políticas que reivindicam a segurança e a saúde no trabalho, clamando pela prevenção e pela promoção de saúde e segurança.

A sociedade civil também é uma tecnologia instrumentalizada na arte de governar, isto é, "uma tecnologia de governo que tem por objetivo sua própria autolimitação, na medida em que é indexada à especificidade dos processos econômicos." (405) Ela surge com o liberalismo alinhado ao homo economicus, portanto, mudanças drásticas no sistema econômico poderiam superar sua validade como 
técnica da arte de governo. A governamentalidade, segundo Foucault (2006, 2008), é constituída por relações de poder que integram processos de resistência. Nos contextos do trabalho, principalmente no que se refere à individualização das responsabilidades, revela-se, principalmente, pela teoria do Capital Humano e seu par o homo oeconomicus.

O Capital Humano é o conjunto de investimentos que foram feitos no próprio trabalhador, desde a sua mais tenra idade, construindo suas competências para a competição no mercado e, segundo Foucault (2008) "permite analisar todos esses comportamentos em termos de empreendimento individual, de empreendimento de si mesmo como investimentos e renda." (317). Portanto, o homo oeconomicus, isto é, - sujeito empresa de si mesmo, apresenta-se como elemento indissociável dos conceitos da tecnologia governamental do neoliberalismo.

A influência da teoria do Capital Humano no campo do trabalho, de acordo com a nossa compreensão sobre o conceito explanado por Foucault $(2006,2008)$, possibilita-nos pensar nos comportamentos e investimentos que regulem a saúde do trabalhador como estratégias para melhorá-la e mantê-la. A concepção neoliberal não considera o trabalho como fonte de valor e, portanto, não o compreende como o centro da produtividade. O trabalho, então, é percebido como uma conduta econômica que resulta em renda. A nosso ver, a teoria do Capital Humano cumpre o seu papel, pois o trabalho como constitutivo do sujeito e gerador de valor precisa ser negado para que os mecanismos gerenciais, igualmente no âmbito da saúde e da segurança do trabalho, sejam justificados.

Entretanto, numa perspectiva avessa a neoliberal, isto é, no campo de estudos sobre o trabalho inspirados no materialismo histórico e dialético, pensamos que o trabalho permanece uma categoria chave para o entendimento das relações de produção, tratando-se de um fazer constitutivo do sujeito que preserva tanto a objetividade quanto a subjetividade sem prescindir de nenhuma delas. Então, os conceitos de trabalho e processo de trabalho conflitam com os conceitos de risco e ambiente, também presentes na redação da PNSTT (Brasil, 2012), o que pode compor um campo de disputa simbólica.

\section{A PNSTT como campo de disputa simbólica}

Procuramos mostrar o método de análise e os principais conceitos que compõe a PNSTT (2012) como uma biopolítica e encontramos certa contradição, que, no que concerne a prática profissional a que a política ilumina, pode compor certa disputa simbólica. Desta forma, apontamos os desafios enfrentados pelos profissionais da saúde pública ao utilizar as políticas de saúde do trabalhador e o plano de 
saúde do trabalhador como dispositivos de referência para a atuação profissional, contrapondo os conceitos que a caracterizam como uma biopolítica com os conceitos que primam pelas ações participativas, coletivas, com inserção multiprofissional no território que deverá considerar a relação entre o meio ambiente e o trabalho como categoria essencial no contexto do Sistema Único de Saúde - SUS. (Brasil, 2012)

A mobilização da PNSTT (2012) e dos conceitos aderentes a ela deve ocorrer por meio da prática profissional, sobretudo, na Rede de Atenção à Saúde do Trabalhador - RENAST - instituída em 11 de novembro de 2009 pela Portaria 2.728 do Ministério da Saúde (Brasil, 2009). De tal modo, a RENAST deve ser articulada pelos Ministérios da Saúde, pelas Secretarias de Saúde dos Estados e Municípios e pelo Distrito Federal. As diretrizes da PNSST (Brasil, 2012) se associam aos princípios do Sistema Único de Saúde - SUS, como reza seu artigo II, de maneira "descentralizada e hierarquizada, em todos os níveis de atenção do SUS, incluindo as de promoção, preventivas, curativas e de reabilitação", voltando-se para ações de promoção, de assistência e de vigilância.

A RENAST compõe um campo de práticas profissionais e proporciona certas possibilidades para ações em assistência e vigilância. Deve privilegiar tanto as ações individuais em saúde perante os agravos advindos do trabalho, quanto alinhar "as ações de planejamento e avaliação com as práticas de saúde" [e privilegiar o] "conhecimento técnico e os saberes, experiências e subjetividade dos trabalhadores e destes com as respectivas práticas institucionais", como exposto no Artigo 60 inciso II e III da PNSTT (Brasil, 2012). Aliado a isso, deve considerar o parágrafo único do mesmo artigo: "A realização da articulação tratada neste artigo requer mudanças substanciais nos processos de trabalho em saúde, na organização da rede de atenção e na atuação multiprofissional e interdisciplinar, que contemplem a complexidade das relações trabalho-saúde." (Brasil, 2012) O processo de trabalho é constituído pelos elementos objetivos, isto é, os instrumentos de trabalho, o objeto de trabalho, as matérias-prima, os meios de trabalho; e pela atividade humana que revela também a subjetividade. (Antunes, 2013; Sartre, 2002). Neste sentido, o processo de trabalho como conceito norteador da política, aparece em duas frentes, ou seja, o processo de trabalho em saúde para o exercício da vigilância e da atenção e como objeto de análise e de intervenção nas organizações de trabalho.

A RENAST foi estruturada em Centros de Referência em Saúde do Trabalhador - CEREST (Brasil, 2009) com a missão de realizar ações de atenção e vigilância e também o matriciamento em saúde do trabalhador. Importante lembrar que essa estrutura se desenvolve a partir de experiências promissoras como aquelas relatadas por Sato, Lacaz e Bernardo (2006). Os pesquisadores destacam que práticas 
que primem pela prevenção e promoção da saúde do trabalhador irão se deparar com o conflito capital-trabalho, pois "Interferir na forma como o trabalho está organizado em favor da saúde dos trabalhadores [...] contradiz os interesses do Capital." (286). Assim, o campo de práticas foi sendo delimitado à medida que as políticas em saúde do trabalhador protagonizaram disputas de classe ao ter as categorias trabalho e processo de trabalho como norteadoras da intervenção e da análise (Gomez, Machado e Pena, 2011).

No campo da saúde do trabalhador, Gomez, Machado e Pena (2011) reiteram que os conceitos de trabalho e de processo de trabalho, na concepção de Marx, são potentes para as análises referentes às situações de trabalho. Assim, pensamos que se faz fundamental ligar os processos de trabalho aos aspectos políticos no sentido de que a ação "[...] é núcleo de significação do mundo" (Ortiz, 1983:12), pois, um campo de práticas profissionais e teóricas "se transformam em um corpo estruturante e estruturado, composto por disposições adquiridas, individual e coletivamente." (29) Sendo que, através da apropriação das ações constituintes do campo de práticas, constituise a disputa pelo poder simbólico que "[...] influencia as percepções, a compreensão das coisas e as ações." Deste modo, faz sentido a importância dada por Lacaz (2013), Gomez, Machado e Pena (2011) e Lapis e Merlo (2007) aos processos de trabalho ligados aos processos de saúde e doença dos trabalhadores marcando, além dos componentes dos processos de trabalho, a forma como ele é organizado e significado.

Costa, Lacaz, Filho e Vilela (2013) questionam "se a publicação recente dos instrumentos legais poderá servir de suporte à melhoria e à efetivação dos serviços." (13) Totalizam suas reflexões aferindo que as políticas tanto podem ser um modo de resistência e de luta através dos quais novas configurações do processo de trabalho podem ocorrer, quanto, propostas tímidas de iniciativas do Estado na regulação do conflito entre capital e trabalho. Neste ponto, pensamos que os conceitos de sociedade civil, ambiente e risco favorecem o controle sobre o indivíduo, pois aprimoram a PNSTT (2012) no sentido do controle sobre a população à medida que o risco é um elemento isolado do ambiente de trabalho que o indivíduo precisa lidar. Neste sentido que a análise do campo de práticas como campo de disputas simbólicas faz-se importante.

O PLANSAT (Brasil, 2012), na direção dos propósitos expressos pelas políticas, versa sobre as estratégias para pôr em prática a PNSST (Brasil, 2011). Afirma os princípios do SUS e mobiliza os conceitos de risco e de ambiente de trabalho, como no seu artigo I:

A Política Nacional de Segurança e Saúde no Trabalho - PNSST tem por objetivos a promoção da saúde e a melhoria da qualidade de vida do trabalhador e a prevenção de acidentes e 
de danos à saúde advindos, relacionados ao trabalho ou que ocorram no curso dele, por meio da eliminação ou redução dos riscos nos ambientes de trabalho.

A PNSTT (Brasil, 2012), equivalente a PNSST (2011), faz uso dos termos ambiente e risco, porém, utiliza outro conceito em particular que nos mostra seu caráter conflitante. Trata-se do conceito de participação que faz valer a potencialidade transformadora de quem trabalha, ou seja, os trabalhadores da rede SUS e os trabalhadores usuários diretos e indiretos dos serviços de saúde. A participação abarca tanto a sociedade civil no seu papel de controle social, quanto às metodologias de pesquisas ação-participante, privilegiando os saberes e experiências dos trabalhadores (Costa, Lacaz, Filho e Vilela, 2013).

O PLANSAT (Brasil, 2012) em acordo com a PNSTT (2012) resguarda a participação nas estratégias de atuação, a exemplo da estratégia 1.4 que versa sobre a participação e prevê a seguinte ação: "Fortalecimento da participação de representantes de trabalhadores e empregadores nas instâncias de controle social em Conferências, Conselhos, Comissões, Grupos de Trabalho etc. (Nacionais, Estaduais e Municipais)" (27). E também vislumbra a participação dos representantes dos trabalhadores em análises de acidentes de trabalho graves ou fatais, considerando, por fim, o conceito de processo de trabalho e de atividades de trabalho como importantes.

Percebemos que a tradição em pesquisa ação participante da Psicologia Social no Brasil tem um papel relevante no que concerne a mobilização das metodologias de pesquisa e ação em situações de trabalho. O resgate do movimento sanitário italiano no Brasil, que no âmbito do trabalho teve o protagonismo de Ivar Oddone (Corrêa, Pinheiro e Merlo, 2013; Sato, Lacaz e Bernardo, 2006) também inspirou o exercício da pesquisa em cooperação com os trabalhadores a partir da experiência deles na discriminação e entendimento dos riscos em ambiente de trabalho, estimulando o coletivo de trabalhadores no campo da luta de classes para mudanças significativas no processo de trabalho em prol da saúde. Neste sentido, tanto a Psicologia do Trabalho, inspirada na Psicologia Social (Coutinho, 2015), quanto o nascente campo de Saúde do Trabalhador (Gomez, Machado e Pena, 2011) afirmam o trabalho, o processo de trabalho e a experiência do trabalhador como conceitos norteadores da reflexão teórica e da prática profissional.

A timidez em relação às funções de vigilância e atenção em saúde do trabalhador que deveriam ser promovidas na rede SUS, sobretudo pelos CEREST's é sustentada, amiúde, por um discurso de conciliação entre os interesses de classe. Mas, se resgatarmos os estudos (Lacaz \& Gomes, 2005; Gomez, 2013) e as práticas profissionais e formas de organização (Lacaz, 2013; Sato, Lacaz e Bernardo, 2006) que 
inspiraram as políticas em saúde do trabalhador no conteúdo que salvaguarda a participação e a escuta dos trabalhadores a partir da experiência deles, podemos entender que se ampararam muito mais na concepção de luta de classes do que na noção de interesse de classe, que se diferenciam. A noção de interesses, como anteriormente relacionada ao desejo do sujeito que pode ser apropriado para uma conciliação, não se aplica, necessariamente, a classe trabalhadora. Sartre (2002) mostra que o interesse da classe dominante, no fim das contas, transforma-se em destino para a classe trabalhadora. Tal interesse é operado das mais diversas formas, a exemplo da individualização da noção de risco quando é mobilizada descolada do processo de trabalho e voltada ao entendimento de trabalho como renda e do trabalhador como homo oeconomicus. Ao contrário da conciliação, no campo de lutas e divergências, a inconformidade com o destino imposto gera conflito entre projetos de sociedade, pois a resistência, com efeito, refere-se à própria condição de pertencer à classe trabalhadora.

Os discursos que compreendem a mediação de interesses entre capital e trabalho são promovidos também pelos atuais modelos de gestão e viabilizam "a desestabilização e o enfraquecimento dos coletivos de trabalho, com a conseqüente diluição e desvalorização da experiência e do saber dos trabalhadores." (Costa, Lacaz, Filho, \& Vilela 2013:14). As narrativas oriundas do sistema privado de produção são afins a racionalidade neoliberal como a da Teoria do Capital Humano e arraigam-se estrategicamente nos serviços públicos de saúde e, especificamente, nos serviços de saúde do trabalhador, embora a PNSTT (Brasil, 2012) contemple os conceitos de trabalho como podemos ver no artigo V: "incorporar a categoria trabalho como determinante do processo saúde-doença." E no artigo VI: "assegurar que a identificação da situação do trabalho dos usuários seja considerada nas ações e serviços de saúde do SUS e que a atividade de trabalho realizada pelas pessoas, com as suas possíveis consequências para a saúde, seja considerada no momento de cada intervenção em saúde". O trabalho, na perspectiva do materialismo histórico e dialético, é uma atividade humana voltada a fins, através do qual o homem modifica o mundo e a si mesmo, categoria central para a compreensão do modo de produção capitalista. A categoria trabalho integra conceitos complexos. Assim, para entendê-la é imprescindível analisar os riscos inerentes a elementos do processo de trabalho e, no que se refere à prática profissional, superar a ideia de conciliação de interesses de classe.

De todo modo, a PNSTT (2012) guarda em si um conjunto de conceitos divergentes. Se considerarmos essa assertiva como válida para refletirmos criticamente sobre essa política podemos supor também que a viabilidade dela na prática profissional nos serviços de saúde de trabalhador pressupõe certa disputa simbólica e um campo 
de possibilidade para práticas promotoras de saúde. Neste sentido, Sartre (2002) contribuiu com nossas análises. O autor fundamentarse no materialismo histórico e dialético reiterando a concepção de luta de classes e dos processos de luta afirmando a centralidade do trabalho como gerador de valor, inspirando o entendimento sobre a importância do papel do conceito de trabalho no âmbito da disputa simbólica. Sartre (2002) postula que: “É verdade que, em uma sociedade inteiramente alienada em que o capital aparece cada vez mais como poder social do qual o capitalista é funcionário, os fins manifestos podem dissimular a necessidade profunda de um mecanismo montado." (118) Os fins proposto pela perspectiva neoliberal são vivenciados como desejos e necessidades naturalizadas. Contra isso o conceito de projeto de ser e campo de possíveis através do qual Sartre (2002) mobiliza a objetividade e a subjetividade nos possibilita refletir sobre as práticas profissionais desnaturalizantes, viabilizadas também pelas políticas públicas em saúde do trabalhador. Para Sartre,

a conduta mais rudimentar deve ser determinada, de uma só vez, em relação aos fatores reais e presentes que a condicione e em relação a um certo objeto por vir que ela tenta fazer nascer. É a isso que damos o nome de projeto. (77)

Sartre (2002) procura mostrar que a ação individual possui desdobramentos que são coletivos:

Portanto, deve-se conceber a possibilidade como duplamente determinada: por um lado, no próprio âmago da ação singular, é a presença do futuro como o que falta e o que desvela a realidade por essa ausência. Por outro, é o futuro real e permanente que mantém e transforma, incessantemente, a coletividade. (79)

Um campo de práticas se desdobra num campo de possíveis. Por isso, cabe refletir sobre o campo de possíveis para a saúde do trabalhador considerando o conceito de processo de trabalho como norteador das práticas em saúde do trabalhador e, ao mesmo tempo, articulador do campo saúde do trabalhador (Lacaz \& Gomes, 2005).

\section{A PNSTT e um campo de práticas em saúde do trabalhador}

A compreensão é um momento da práxis, decorrendo dela possivelmente uma experiência que só pode ser vivida por um sujeito e ganha força à medida que é compartilhada com os demais. (Sartre, 2002). Neste sentido, Sartre (2002) discute sua teoria de grupo e 
diferencia a reciprocidade, ou seja, reconhecimento da humanidade em si mesmo e no Outro, e a coisificação, isto é, conceber o Outro como coisa deixando de considerar a sua humanidade. A constituição de grupos ocorre por meio da solidariedade, que se traduz em práticas intimamente ligadas à reciprocidade. Elas existem à proporção que alguém as realiza e a reflexão sobre a experiência em realizá-las ocorre, constituindo certo campo de possibilidades históricas em que as experiências tornam-se possíveis mediante certo campo de práticas. Neste caso, poderíamos traduzir esta perspectiva para a prática profissional no Campo da Saúde do Trabalhador a que a PNSTT (2012) tem a função de iluminar.

No que concerne a questão dos serviços em saúde pública, a responsabilização individualizada como estratégia de controle afeta o sujeito que trabalha e, igualmente, as formas de solidariedades, imprescindíveis para a organização dos trabalhadores dentro e fora dos locais de trabalho. Neste sentido, no Capítulo III na PNSTT (2012) que versa sobre as estratégias, no item $\mathrm{VI}$ (a) sobre a capacitação dos recursos, humanos, encontramos a preocupação com a precarização do trabalhador nos serviços públicos de saúde, ao sugerir a desprecarização através do estabelecimento de vínculo trabalhista mediante concurso público, embora, no que se refere ao perfil dos processos produtivos do território, bem como, ao estímulo a participação dos trabalhadores, o foco permanece nos riscos do ambiente de trabalho.

No âmbito do trabalho, Ramminger e Nardi (2008) mostram que a governamentalidade neoliberal está presente nas mais variadas maneiras de gerir, a exemplo da ênfase ao trabalho flexível inerente a precarização do trabalho, que significa desregulamentação do contrato de trabalho e das atividades (Galeazzi e Holzmann, 2011). Pertence ao mesmo domínio de referências conceituais que promovem a precarização do trabalho, o trabalhador flexível, que, de acordo com Ramminger e Nardi (2008) “[...] é autônomo, flexível, enxuto (mas não só ele, também as instituições e o Estado), assumindo integralmente a responsabilidade por sua atividade, bem como por suas possíveis falhas." (344) Os modelos de gestão que regulam inumeráveis práticas laborais adotam o referencial do trabalhador flexível de modo que a responsabilidade individual é ressaltada seja no que diz respeito à produtividade de acordo às metas, seja referente aos acidentes e doenças ocupacionais analisados a partir dos riscos reduzidos ao ambiente laboral, desconsiderando, em parte, a complexidade dos processos de trabalho.

Entretanto, ao mesmo tempo, no Anexo I, que aborda "os elementos informativos da política nacional de saúde do trabalhador e da trabalhadora", há o cuidado em definir a promoção da saúde em ambientes e processos de trabalho. Além de determinar que a 
articulação das ações em promoção deva ocorrer entre a PNSTT (2012) a PNSST (2011) e ao SUS, afirmando a importância das ações que prezem pelo trabalho descente. No item 8 do anexo 1, por exemplo, sugere a promoção de “[...] relações éticas e de respeito nos locais de trabalho, o reconhecimento do direito dos trabalhadores à informação, à participação e à livre manifestação" e também, a identificação da vulnerabilidade e o combate a violência no trabalho.

É preciso levar em conta que as práticas individualizantes podem estar se tornando hegemônicas e, muitas vezes, são consideradas por quem as realiza como naturais. No caso da prática profissional nos serviços de saúde do trabalhador pode aparecer como demanda compor interesses diversos, tal como apregoa a teoria do Capital Humano, naturalizando os conflitos de classe que decorre em lidar com os riscos para que os recursos humanos possam continuar produzindo (Silveira, Perez, e Santos, 2014). Gonçalves (2010) situa o problema e pondera sobre a relevância de "considerar as demandas da realidade social a partir de uma perspectiva histórica, procurando a desnaturalização dos fenômenos sociais". (63) Neste sentido, a categoria risco contempla somente a objetividade da situação de trabalho desconsiderando o sujeito. Vale lembrar as lições de Oddone (1986) sobre a experiência italiana, em que o mapeamento dos riscos em ambiente de trabalho foi uma construção coletiva que viabilizava a organização dos trabalhadores dentro e fora do local de trabalho resultando na historicização dos riscos, na compreensão sobre a constituição deles e numa experiência de luta pelo controle dos processos de trabalho.

Como demarca Campos (1997) sempre cabe decidir se "[...] em todos estes espaços se construiria o novo ou se reforçaria a velha dominação." ( $(\mathrm{n} / \mathrm{n})$ Assim, pensamos que se faz importante realizar análises dos conceitos que atravessam a PNSTT (Brasil, 2012) em função da concepção que Ihes são inerentes e das possibilidades de atuação profissional que criam. Barros e Pimentel (2012), por exemplo, indicam que a prática em políticas públicas pode pautar-se na construção do comum, interferindo "nos processos que constituem as realidades e não partir das realidades como aspectos sempre já dados." (06) Valorizam, sobretudo, o conceito de território não apenas como a delimitação geográfica da atuação, mas como lugar da experiência, promovendo encontros, análises da dinâmica institucional e interlocução entre saberes.

Benevides e Passos (2005) destacam que a palavra humanização foi objeto de disputas quanto ao seu significado na PNH - Política Nacional de Humanização (Brasil, 2004; Brasil 2005). Para os autores, a humanização no âmbito da saúde coletiva implica na produção de subjetividade no trabalho em saúde e torna presente o movimento instituinte do SUS, o que, a nosso ver, compõe uma reflexão fundamental sobre as práticas profissionais. Não 
encontramos, no entanto, referências à Humanização na PNSTT (Brasil, 2012) embora esteja prevista a interface com as demais políticas que devem nortear as práticas profissionais e a concepção de trabalho descente.

As contribuições de Benevides e Passos (2005) e Barros e Pimentel (2012) nos levam a considerar que é estratégico articular a PNSTT (Brasil, 2012) com a PNH (Brasil, 2004), objetivando a superação da Clínica Degradada que Campos (1997) indica como a negação dos preceitos éticos, metodológicos e teóricos em nome de um equilíbrio entre diferentes interesses. Ao contrário, o exercício profissional em políticas públicas como produtora de sentido procura superar, o que Ferreira (2014) afere ao discutir a produção literária como "à condição cronicamente deficitária das tentativas de significar o real." (718). Afirma o autor, entretanto, que a palavra e suas significações "fazem nascer sentidos que não existiam, são produtoras de sentidos em ato. Composição de sentidos nunca estabelecida em definitivo, que está sempre por se fazer." (718) Deste modo, os profissionais devem propor a reflexão crítica sobre as vivências em situações de trabalho, possibilitando ações transformadoras e levando em conta que as políticas que iluminam sua prática necessitam ser problematizadas no que diz respeito ao campo simbólico, visto que, abarcam conceitos que podem implicar uma disputa de sentidos para quem trabalha nos serviços e para quem usufrui deles.

\section{Considerações finais}

A PNSTT (2012) se constitui e opera como uma biopolítica à medida que propõe como objeto a população trabalhadora e prevê as condutas para assegurar a saúde da população de trabalhadores. Ao mesmo tempo, a redação da PNSTT (2012) dispõe dos conceitos de tal modo que poderá envolver certa disputa simbólica em virtude da significação deles, portanto, do impacto que produzem na prática profissional dos trabalhadores dos serviços e daqueles que dele usufruem. Entendemos, então, que os conceitos de risco e ambiente de trabalho guardam sua relevância desde que permaneçam no Campo da Saúde do Trabalhador articulados a categoria de processo de trabalho e de trabalho como reguladores de práticas e análises sobre as realidades de trabalho e sobre a própria prática em saúde do trabalhador.

Os conceitos de trabalho e processo de trabalho viabilizam o movimento compreensivo sobre as práticas profissionais orientadas pelas políticas em saúde do trabalhador, pois, articula-as aos processos saúde e doença. O conhecimento proporcionado aos trabalhadores pela compreensão deles sobre suas próprias práticas se constitui enquanto é compartilhado, e assim, deverá oportunizar 
movimentos de solidariedade. Deste modo, a promoção e a prevenção da saúde tanto na atenção e na vigilância quanto no matriciamento poderão instituir-se, bem como, a participação efetiva dos trabalhadores, tal como versam as políticas de saúde e em particular as que discutimos.

Importante lembrar, por fim, que as análises da PNSTT (2012) que fizemos precisariam, ainda, ser atestadas no próprio campo prático. Deste modo, acreditamos que as análises realizadas poderão contribuir para: conduzir o resgate histórico da PNSTT (2012) como biopolítica e a atual conexão com o neoliberalismo no Brasil; além de identificar a disputa simbólica inerente a PNSTT (2012) e suas nuances no campo prático.

\section{Referências}

Antunes, R. (2013). A dialética do trabalho: escritos de Marx e Engels. São Paulo: Expressão Popular.

Bauer, M. W., \& Aarts, B. (2015). A construção do corpus: um princípio para a coleta de dados qualitativos. In Bauer, M. W. \& Gaskell, G. Pesquisa qualitativa, com texto, imagem e som: Um manual prático (pp. 39-63). Petrópolis: Editora Vozes.

Barros, M. E. B., \& Pimentel, E. H. C. (2012). Políticas públicas e a construção do comum: Interrogando práticas PSI. Polis e Psique, 2(2), 3-22.

Benevides, R. \& Passos, E. (2005). E. A humanização como dimensão pública das políticas de saúde. Ciências e Saúde Coletiva, 10(3), 564-571.

Brasil (2005). HumanizaSus: a clínica ampliada. Ministério da Saúde. Brasília.

Brasil (2009). PORTARIA № 2.728, DE 11 DE NOVEMBRO DE 2009. Dispõe sobre a Rede Nacional de Atenção Integral à Saúde do Trabalhador (RENAST) e dá outras providências. Ministério da Saúde. Brasília.

Brasil (2011). DECRETO № 7.602, DE 7 DE NOVEMBRO DE 2011. Dispõe sobre a Política Nacional de Segurança e Saúde no Trabalho - PNSST. Brasília.

Brasil (2009). PORTARIA № 2.728, DE 11 DE NOVEMBRO DE 2009. Dispõe sobre a Política Nacional de Saúde do Trabalhador e da Trabalhadora. Ministério da Saúde. Brasília.

Brasil (2012). Plano Nacionacional de Segurança e Saúde do Trabalhador. CT-SST - Comissão Tripartite de Saúde e Segurança do Trabalhador. Brasília.

Campos, G. W. S. (1997). A clínica do sujeito: por uma clínica reformulada e ampliada. Disponível em: www. gastaowagner.com. br/index. php? preview=1\&option=com 
dropfiles\&format $=\&$ task $=$ frontfile. download\&catid $=21 \& i d=51 \&$ Itemid $=1000000000000$

Corrêa, M. J. M., Pinheiro, T. M. M., \& Merlo, A. R. C. (2013). Vigilância em Saúde do Trabalhador no Sistema Único de Saúde: teorias e práticas. Belo Horizonte: COOPMED.

Costa, D., Lacaz, A. C, Filho, J. M. J., \& Vilela, R. A, G. (2013). Saúde do Trabalhador no SUS: desafios para uma política pública. Revista Brasileira de Saúde Ocupacional, 38(127), 11-30.

Coutinho, M. C. (2015). Psicologia Social em dois tempos. In Coutinho, M. C., Furtado, O. \& Raitz, T. R. Psicologia Social e Trabalho: perspectivas críticas (pp. 3-15). Florianópolis: Edições do Bosque.

Ferreira, J. B. O. (2014). Sobrevivências, clandestinidades, lampejos: o trabalho vivo da criação literária. Fractal, 26(n. esp.), 715728.

Foucault, M. (1979). A política de saúde no século XVIII. In Foucault, M. (1979). Microfísica do poder (pp. 193-207). Rio de Janeiros: Edições Graal.

Foucault, M. (2006). Segurança, Território e População - Curso dado no Collège de France (1977-1978). São Paulo: Martins Fontes.

Foucault, M. (2008). Nascimento da Biopolítica - Curso dado no Collège de France (1978-1979). São Paulo: Martins Fontes.

Galeazzi, I. \& Holzmann, L. (2011). Precarização do Trabalho. In Cattani, A. D. \& Holzmann, L. Dicionário de Trabalho e Tecnologia (pp. 259-265). Porto Alegre: Zouk.

Gomez, C. M. (2013). Avanços e entraves na implementação da Política Nacional de Saúde do Trabalhador. Revista Brasileira Saúde Ocupacional, 38(127), 11-30.

Gomez, C. M., Machado, J. M. H., \& Pena, P. J. L. (2011). Saúde do Trabalhador $\mathrm{Na}$ Sociedade Brasileira Contemporânea. Rio de Janeiro: Fiocruz.

Gonçalves, M. G. M. (2010). Psicologia, Subjetividade e Políticasúblicas. São Paulo: Cortez.

Lacaz, A. C. \& Gomez, C. M. (2005). Saúde do Trabalhador: novas e velhas questões. Ciência e Saúde Coletiva, 10(4), 797-807.

Lacaz, A. C. (2013). Vigilância em saúde do trabalhador como elemento constitutivo da saúde do trabalhador no Sistema Único de Saúde (SUS): aspectos históricos e conceituais. In Corrêa, M. J. M., Pinheiro, T. M. M., \& Merlo, A. R. C. Vigilância em Saúde do Trabalhador no Sistema Único de Saúde: Teorias e Práticas (pp. 35-60). Belo Horizonte: Coopmed.

Lapis, N. L. \& Merlo, A. R. C. (2007) A saúde e os processos de trabalho no capitalismo: reflexões na interface da psicodinâmica do trabalho e da sociologia do trabalho. Psicologia \& Sociedade, 19(1), 61-68. 
Oddone, I. (1986). Ambiente de Trabalho: a luta dos trabalhadores pela saúde. Editora Hucitec: São Paulo.

Ortiz, R. (1983). A Procura de Uma Sociologia da Prática. In Bourdieu, P. Pierre Bourdieu: Sociologia. (pp. 7-36). São Paulo: Ática.

Ramminger, T., \& Nardi, H. C. (2008). Subjetividade e trabalho: algumas contribuições conceituais de Michel Foucault. Interface - Comunicação, Saúde e Educação, 12(25), 339-46.

Sartre, J. P. (2002). Crítica da razão dialética. Rio de Janeiro: Ed. DpeA.

Sartre, J.P. (2013). O idiota da família: Gustave Flaubert de 1821 a 1857. Porto Alegre: E\&PM.

Sato, L., Lacaz, F. A. C. \& Bernardo, M. H. (2006). Práticas e investigações na Saúde Pública de São Paulo. Estudos de Psicologia, 11(3), 281-288.

Silveira, A. L. Perez, K. V. \& Santos, V. M. (2014). Naturalização das demandas para a Psicologia: uma questão atual. Revista Polis e Psique, 4(2), 188-205.

\section{Endereço para correspondência \\ Andréa Luiza da Silveira}

Universidade Comunitária da Região de Chapecó - Unochapecó

Av. Senador Atílio Fontana, 591-E, Efapi, Caixa Postal 1141, CEP 89809-000, Chapecó - SC, Brasil

Endereço eletrônico: deasilveira@gmail.com

Álvaro Roberto Crespo Merlo

Universidade Federal do Rio Grande do Sul - UFRGS

Rua Ramiro Barcelos, 2600, Térreo, CEP 90035-003, Porto Alegre - RS, Brasil

Endereço eletrônico: merlo@ufrgs.br

Recebido em: 11/09/2015

Reformulado em: 18/12/2016

Aceito em: 28/03/2017

\section{Notas}

* Doutoranda Pós-graduação em Psicologia Social e Institucional - UFRGS. Professora do Curso de Psicologia da Unochapecó, Chapecó/SC.

** Professor da Pós-graduação em Psicologia Social e Institucional - UFRGS.

Este artigo de revista Estudos e Pesquisas em Psicologia é licenciado sob uma Licença Creative Commons Atribuição-Não Comercial 3.0 Não Adaptada. 